\title{
Uso de índice espectral para monitoramento da cobertura vegetal no município de Juazeiro do Piauí
}

\author{
Uses of spectral indexes to monitor vegetation cover in the municipality of Juazeiro do Piauí \\ SANTOS $^{1}$, F.A. \\ francilio.amorim@ifpi.edu.br.
}

\section{Resumo}

O objetivo do estudo foi realizar uma análise espaçotemporal das condições da cobertura vegetal no município de Juazeiro do Piauí, por meio do índice de vegetação ajustado ao solo (IVAS). Para operacionalização e análise espaço-temporal da cobertura vegetal foram adquiridas imagens da série Landsat, para os anos de 1997, 2006 e 2016. O município estudado apresenta distintas fisionomias para a vegetação do tipo caatinga, que varia do porte herbáceo a arbustivo e arbóreo, além da presença de cerrado rupestre. Os resultados indicaram predomínio das classes de vegetação com atividade fotossintética alta a muito alta nos anos de 1997, ocupando $41,6 \%$ do município, e 2006, distribuindo-se por 58,2\% da área. Por outro lado, houve significativa redução de ambas as classes em relação ao ano de 2016, quando figurou apenas a classe de atividade fotossintética alta, encontrada em $0,03 \%$ do município. Essas mudanças nos padrões fisionômicos da vegetação devem está ligadas à ocorrência dos fenômenos oceânicos El niño e La niña. Desse modo, fica evidente a importância do monitoramento da cobertura vegetal por meio do uso de índices espectrais, visto que a redução da vegetação pode gerar o desencadeamento de processos erosivos e, posterior, desequilíbrios nos sistemas ambientais.

Palavras-chave: Vegetação, Área Suscetível à Desertificação, IVAS.
Abstract

The objective of the study was to perform a space-time analysis of the vegetation cover conditions in the municipality of Juazeiro do Piauí, using the vegetation index adjusted to the soil (SAVI). Landsat images were acquired for the years 1997, 2006 and 2016. The studied municipality presents several physiognomies for a vegetation of the caatinga type that varies from herbaceous to shrubby and arboreal, besides the presence of cave enclosure. The results indicated the predominance of vegetation classes with high activity, very high in 1997, occupying $41.6 \%$ of the municipality and 2006 , being distributed by $58.2 \%$ of the area. On the other hand, there was a significant reduction of activities as classes in relation to the year 2016, when it was only the class of high photosynthetic activity found in $0.03 \%$ of the city. These changes in the physiognomic patterns of the vegetation are predicted for the occurrence of the oceanic phenomena El niño e La niña. Thus, the importance of monitoring vegetation cover through the use of indexes is evident, which can reduce the propagation of the process of generating erosion processes and, later, imbalances in environmental systems.

Keywords: Vegetation, Area Susceptible to Desertification, SAVI.

\section{INTRODUÇÃO}

$\mathrm{O}$ aumento das áreas destinadas às práticas das atividades humanas, notadamente aquelas ligadas à agropecuária e extrativista, tem gerado perturbações ao equilíbrio natural dos sistemas ambientais, tendo em vista que demandam a supressão da cobertura vegetal. Nessa ótica, os estudos 
ambientais devem inserir a ação humana como elemento modificador do quadro natural, visto que interferem no fluxo de energia e de matéria no âmbito dos sistemas ambientais.

Nesse contexto, Mendonça (1989) destaca que a temática relacionada à degradação ambiental tem se apresentado como um dos principais objetos em estudo pela Geografia Física, ao passo que seu caráter ambientalista tem gera a possibilidade de compreender a organização social à luz das interferências humanas nos processos naturais.

Cabe ressaltar que dentre os diversos elementos que compõem a paisagem, a vegetação é considerada a síntese desses elementos, visto que sua fisionomia é fator resultante notadamente dos elementos climáticos e tipologias de solos. A vegetação constitui-se fator preponderante no controle do balanço morfogenético e, como atesta Tricart (1977), atenua a erosão pluvial, influencia o regime hídrico e por meio das folhas intercepta as precipitações, amortece a velocidade das gotas e diminui a velocidade do vento.

Nesse contexto, diversos índices têm sido utilizados para monitoramento da cobertura vegetal, notadamente em áreas suscetíveis à desertificação (ASD). Esta considerada um tipo específico de degradação que ocorre em áreas áridas, semiáridas e subúmidas secas, produto das variações climáticas e intensificada pelo uso inadequado dos solos (BRASIL, 1995). De acordo com Nimer (1988), a desertificação está ligada a um desequilíbrio natural, cuja retroalimentação negativa dos ecossistemas não é totalmente recompensada pela retroalimentação positiva.

As ASD ocorrem por todos os continentes, atingindo principalmente aqueles países situados em zonas climáticas subúmidas secas e semiáridas. As ASD no Brasil distribuem-se pelos nove estados da região Nordeste, além do norte de Minas Gerais e do Espírito Santo, na região Sudeste, abrangendo uma área de 1.488 municípios, que apresentam clima do tipo subúmido seco e semiárido (BRASIL, 2004; 2007). Dentre esses municípios encontra-se o município de Juazeiro do Piauí, objeto foco do presente estudo (Figura 01). Desse modo, justifica-se o desenvolvimento de estudo voltado ao monitoramento da cobertura vegetal nesse município, tendo em vista que a supressão da vegetação poderá desencadear processos de degradação ou acelerar aqueles existentes.

Dentre os índices espectrais utilizados para monitoramento da cobertura vegetal, o presente estudo utilizou o Index of Vegetation Adjusted to Soil (SAVI, em português índice de vegetação ajustado ao solo - IVAS). O SAVI considera os efeitos do solo exposto nas imagens estudadas, a partir do ajuste do índice de vegetação por diferença normalizada (NDVI) quando a superfície não está totalmente recoberta pela vegetação (BORATTO; GOMIDE, 2013). O índice é utilizado para 
quantificar a perda/ganho da cobertura vegetal e permite mensurar a densidade de fitomassa foliar fotossinteticamente ativa e o nível de umidade por unidade de área.

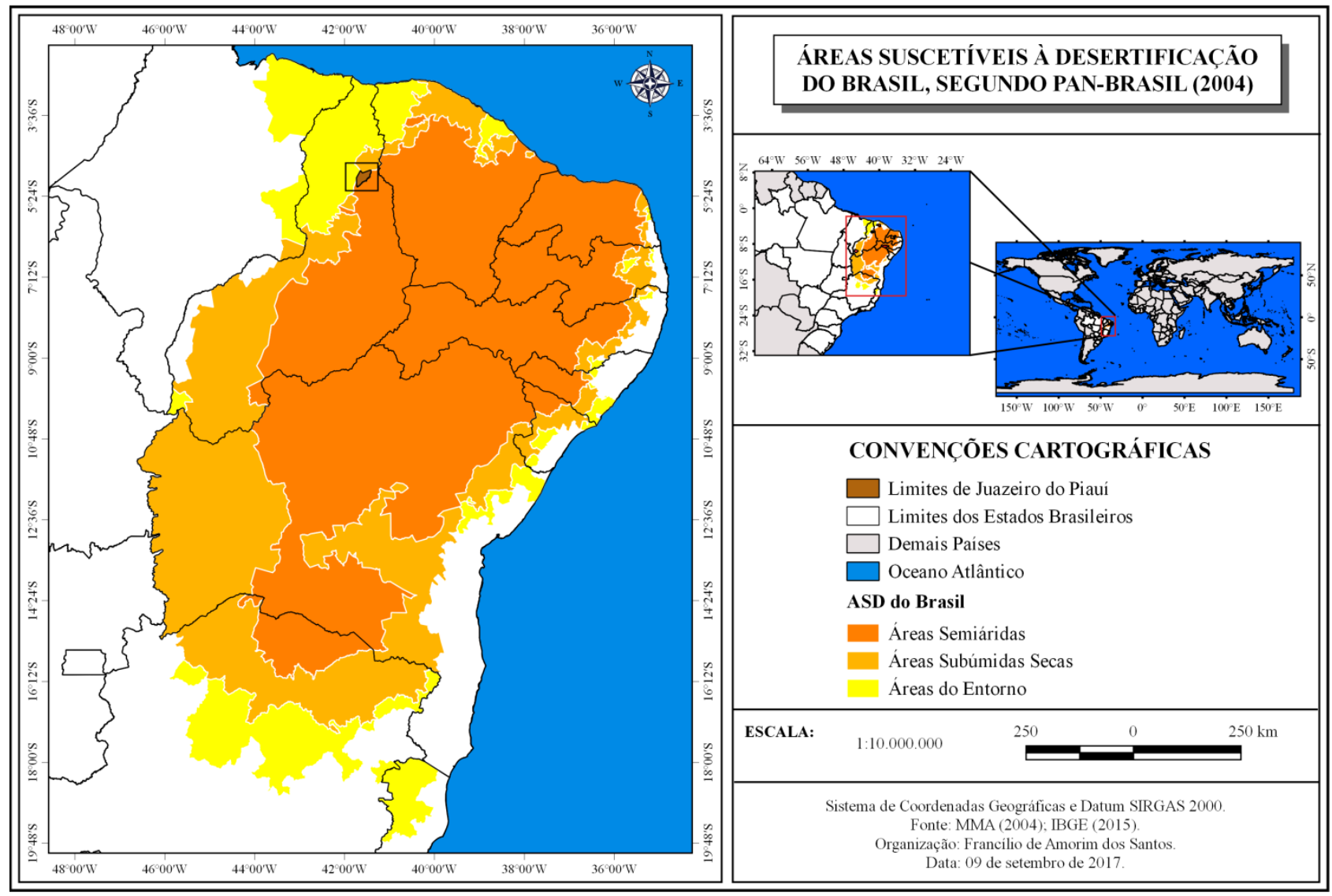

Figura 01. Áreas Suscetíveis à Desertificação do Brasil. Fonte: MMA (BRASIL, 2004); IBGE (2015).

Adaptado pelo autor (2017).

Nesse cenário, é oportuno destacar que distintos estudos têm sido desenvolvidos com foco no monitoramento da cobertura vegetal empregando o SAVI, entre eles citam-se os seguintes: Boratto e Gomide (2013) que se utilizaram dos índices NDVI, SAVI e IAF para a caracterização da vegetação do Norte de Minas Gerais, a partir de análises espectrais de imagens do satélite Landsat 5 TM; Figueirêdo et al. (2013) utilizaram os índices NDVI e SAVI, associado a técnicas de sensoriamento remoto, para avaliar a cobertura vegetal da Bacia do Alto Ipanema (PE); Braz et al. (2015) realizaram análise multitemporal da dinâmica da cobertura vegetal via índices NDVI e SAVI na Bacia Hidrográfica do Córrego Ribeirãozinho, Selvíria (MS).

Diga-se, também, que o SAVI apresenta sensibilidade a quantidade de água disponível no meio, seja no solo ou na folhagem das árvores e, como tal, está sujeito às oscilações dos totais pluviométricos. Estes sofrem influência dos fenômenos El niño e La niña, sendo que o primeiro resulta do aquecimento das águas do Oceano Pacífico e é responsável por anos secos, enquanto o 
segundo é produto do resfriamento anômalo das águas do citado oceano e gera anos considerados normais ou chuvosos no Nordeste do Brasil (NEB), conforme atestam Ferreira e Mello (2005).

Considerando-se que a vegetação constitui importante elemento da dinâmica da paisagem, particularmente como regulador do balanço morfogenético, com as devidas adaptações em relação à área em estudo, considerada suscetível à desertificação, o presente estudo propôs-se a realizar uma análise espaço-temporal das condições da cobertura vegetal no município de Juazeiro do Piauí, por meio do índice de vegetação ajustado ao solo.

\section{METODOLOGIA}

\subsection{Localização e caracterização da área em estudo}

O estudo foi realizado no município de Juazeiro do Piauí, suja sede municipal está situada às coordenadas $05^{\circ} 10^{\prime} 19^{\prime \prime} \mathrm{S}$ e $41^{\circ} 42^{\prime} 10^{\prime \prime} \mathrm{O}$ (Figura 02), que está localizada há $158 \mathrm{~km}$ de Teresina, capital do estado do Piauí. O referido município abrange uma área de $827,2 \mathrm{~km}^{2}$ (AGUIAR; GOMES, 2004) e uma população estimada para 2017 de 5.391 mil habitantes (IBGE, 2017).

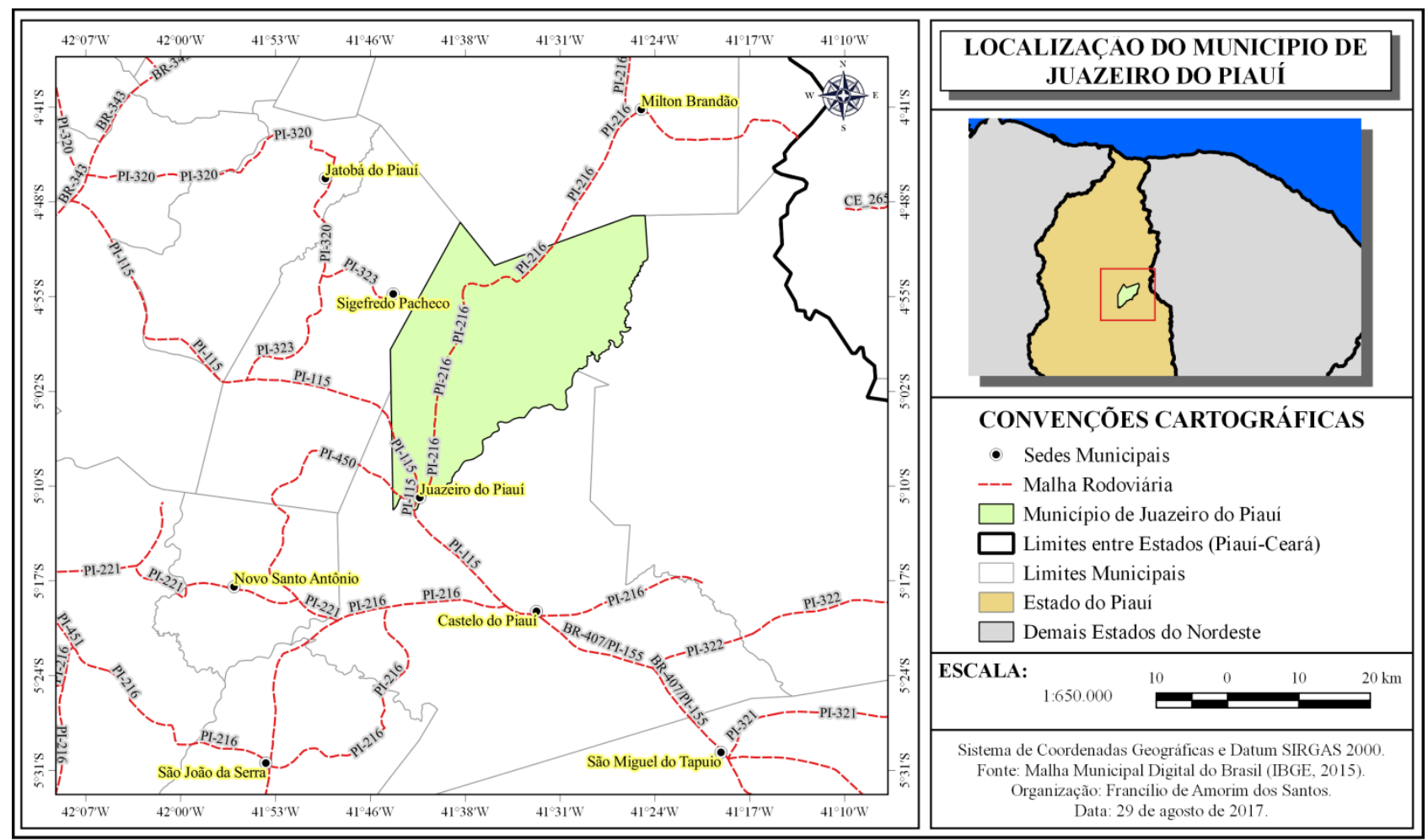

Figura 02. Localização do município de Juazeiro do Piauí. Fonte: IBGE (2015). Organizado pelo autor (2017). 
O município supracitado está assentado sobre formações geológicas preponderantemente sedimentares, que datam da Era Paleozoica, quais sejam: Formação Cabeças, que abrange 78,2\% da área, e a Formação Pimenteiras, que se estende por 21,8\% do município (CPRM, 2006). O relevo apresenta cotas altimétricas que variam de $100 \mathrm{~m}$ a $260 \mathrm{~m}$ e declividade predominantemente plana a suave ondulada (SANTOS, 2015).

O município em questão localiza-se no médio curso da Bacia do rio Poti, além deste o rio Parafuso e riacho Vertente também drenam o município. De acordo com Santos (2015), a área estudada apresenta pluviometria que varia de $1.000 \mathrm{~mm}$ a aproximadamente $1.200 \mathrm{~mm}$. Em relação às tipologias de solos, foram identificadas três subordens, a saber: os Neossolos Litólicos, os Neossolos Quartzarênicos e os Planossolos Háplicos que ocupam, respectivamente, 39,2\% (324,3 $\left.\mathrm{km}^{2}\right), 13,1 \%\left(108,4 \mathrm{~km}^{2}\right)$ e $3,1 \%\left(25,6 \mathrm{~km}^{2}\right)$ da área do município estudado (INDE, 2014).

\subsection{Procedimentos metodológicos}

Para análise espaço-temporal da cobertura vegetal por meio do emprego do SAVI foram adquiridas imagens via satélite Landsat 5 TM e Landsat 8 OLI, junto ao United States Geological Service (USGS, Serviço Geológico dos Estados Unidos - SGEU), distribuídas gratuitamente no site <http://earthexplorer.usgs.gov/>. As cenas possuem as seguintes características: órbita/ponto 218/63 e 218/64, resolução espacial de 30 metros e as seguintes datas de passagem: 28/07/1997 e 06/08/2006 (Landsat 5); 01/08/2016 (Landsat 8). Esta última passou por processo de conversão radiométrica (16 para 8 bits) via ferramentas do SIG QGIS.

Realizados esses procedimentos, aplicou-se a equação 1 do SAVI no referido SIG. Desse modo, foi possível executar processo de fatiamento para delimitação das classes do SAVI, que variaram de solo exposto à cobertura vegetal com baixa a muito alta atividade fotossintética (Tabela $01)$.

$S A V I=\frac{(N I R-R)}{(N I R+R+L)} *(1+L)$

Onde: $\mathrm{SAVI}=$ é o índice de vegetação ajustado ao solo; $\mathrm{NIR}=$ comprimento de onda correspondente ao infravermelho próximo (TM-4 e OLI-5); $\mathrm{R}=$ comprimento de onda correspondente ao vermelho (TM-3 e OLI-4); L corresponde a uma constante chamada de fator de ajuste do índice SAVI, que nesse estudo assumiu o valor de 0,5, aplicado à vegetação com densidade intermediária. 
Tabela 01. Intervalos do SAVI e classes de vegetação. Fonte: Cerqueira e Santos (2017).

\begin{tabular}{cc}
\hline Intervalos do SAVI & Classes de vegetação \\
\hline$<0$ & Solo exposto \\
$0 \mid--0,1$ & Vegetação com muito baixa atividade fotossintética \\
$0,1 \mid--0,3$ & Vegetação com baixa atividade fotossintética \\
$0,3 \mid--0,5$ & Vegetação com média atividade fotossintética \\
$0,5 \mid--0,7$ & Vegetação com alta atividade fotossintética \\
$0,7|-| 0,9$ & Vegetação com muito alta atividade fotossintética \\
\hline
\end{tabular}

Ressalta-se que foram adquiridos dados do fenômeno El Nino Oscilação Sul (ENOS), junto ao site <http://www.cpc.ncep.noaa.gov>, do Centro de Previsão Climática, para os anos analisados no SAVI. Esse procedimento foi realizado como forma de correlacionar as mudanças no padrão de fisionomia da cobertura vegetal à ocorrência de anos secos ou chuvosos. Pois as oscilações pluviométricas têm influência sobre as variações das classes do SAVI, visto que este apresenta sensibilidade à quantidade de água disponível durante o imageamento da área estudada.

Menciona-se, também, que foi obtido arquivo vetorial dos solos da Folha SB.24 - Jaguaribe, disponibilizado no site <http://www.visualizador.inde.gov.br/>, da Infraestrutura Nacional de Dados Espaciais (INDE, 2014), como tentativa de relacionar os padrões fisionômicos da cobertura vegetal e o substrato pedológicos que as sustenta.

\section{RESULTADOS E DISCUSSÃO}

A priori, cabe relembrar que o SAVI constitui uma forma de mensurar a quantidade de água líquida presente na cobertura vegetal. Desse modo, sua variação está diretamente vinculada ao período em que as imagens de satélite foram selecionadas. Ressalta-se que a vegetação do Nordeste do Brasil (NEB) exibem grandes variações, notadamente das áreas subúmidas secas e semiáridas, visto que os totais de precipitação oscilam significativamente espaço-temporalmente.

A fisionomia da cobertura vegetal no município de Juazeiro do Piauí apresentam distintas fisionomias para a caatinga, exibindo porte herbáceo a arbustivo e arbóreo, apresentando baixo porte e, geralmente, distribuindo-se de forma esparsa. Destaca-se, também, a ocorrência da vegetação rústica denominada de cerrado rupestre, que pode ser encontrado sobre os afloramentos rochosos e às margens dos cursos d'água, a exemplo das margens do rio Poti (Figura 03). 


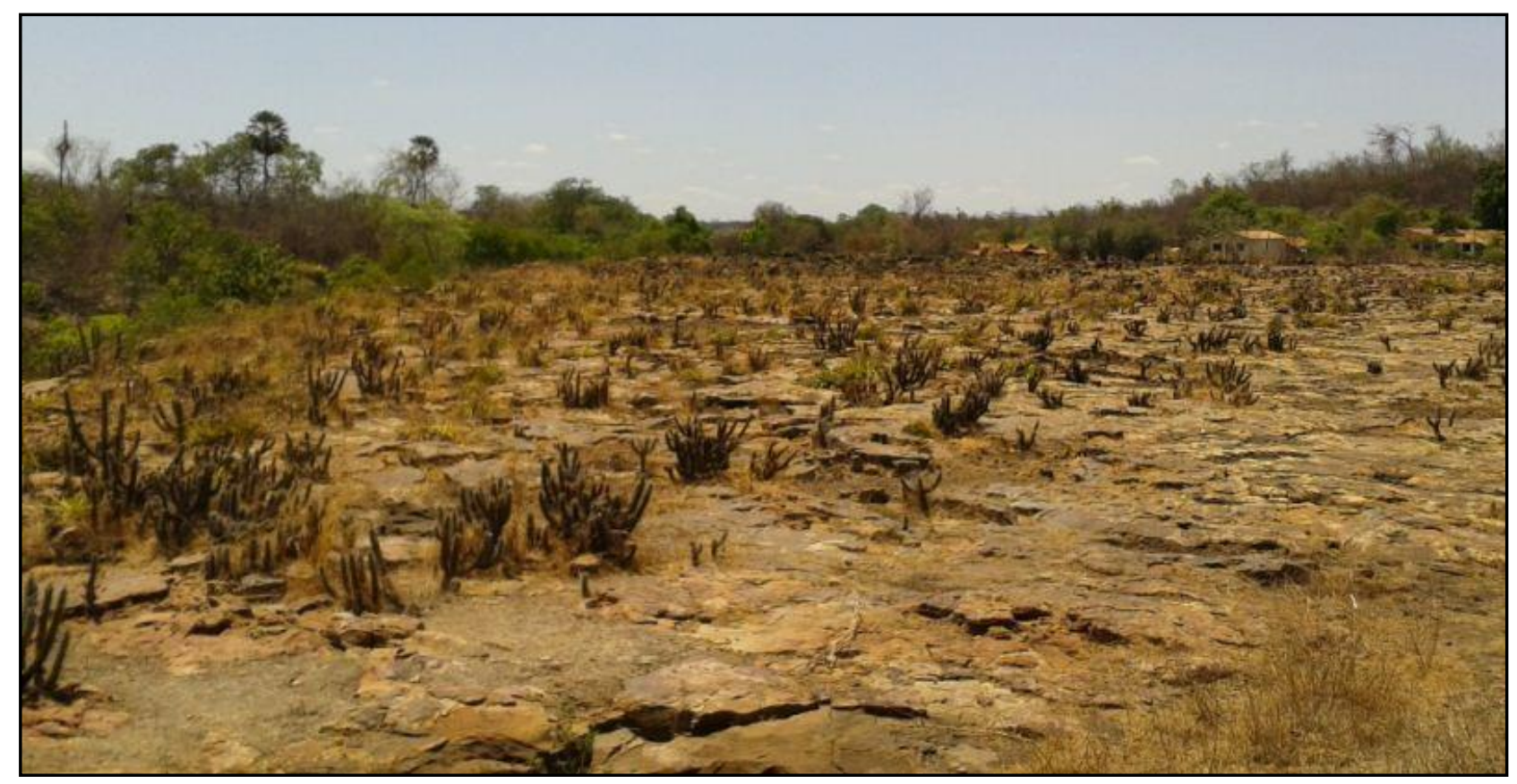

Figura 03. Cerrado rupestre encontrado no vale do rio Poti. Fonte: Arquivo do autor (2017).

Destaca-se que a caatinga arbórea ocorre predominantemente sobre latossolos. Estes geralmente são solos muito intemperizados, profundos e de boa drenagem, apresentam evolução bastante avançada com atuação expressiva de processo de latolização (IBGE, 2007; EMBRAPA, 2009; INDE, 2014). Ressalta-se que devido seu nível de desenvolvimento, profundidade e boa drenagem, além do fato que na área estudada esse tipo de solo é encontrado em áreas de relevo plano e suave ondulado, possibilita o crescimento da vegetação de maior porte.

Por sua vez, os neossolos, que estão em via de formação e constituem-se por material mineral ou material orgânico pouco espesso, e os planossolos, que se apresentam como solos minerais, imperfeitamente ou maldrenados e horizonte superficial ou subsuperficial eluvial (INDE, 2014; IBGE, 2007; EMBRAPA, 2009) sustentam uma vegetação com menor fisionomia, particularmente a caatinga de porte herbáceo e arbustivo.

O cerrado rupestre compreende uma fitofisionomia herbáceo-arbustiva, que particularmente ocorre em afloramentos rochosos, em maciços rochosos quartzíticos ou calcáreos, cujas áreas compõem-se por solos litólicos e pouco profundos. Essa tipologia de vegetação é bem distinta, exibe composição florística diversificada, presença de espécies endêmicas e, no caso do Piauí, ocorre em baixas cotas altimétricas (ALBINO, 2005). 
A análise do SAVI para o ano de 1997 permitiu inferir que as classes de atividade fotossintética alta a muito alta predominaram na área estudada (Figura 04), ocorrendo por 41,6\% do município estudado, notadamente na parte centro-sul e nordeste, onde existia uma vegetação de porte arbóreo. Diga-se, ainda, que as classes de solo exposto e muito baixa atividade fotossintética foram identificadas por $0,1 \%$ e 1,5\% do município, respectivamente. As classes de baixa e média atividade fotossintética ocorreram em $25,0 \%$ e $31,8 \%$ da área pesquisada, respectivamente.

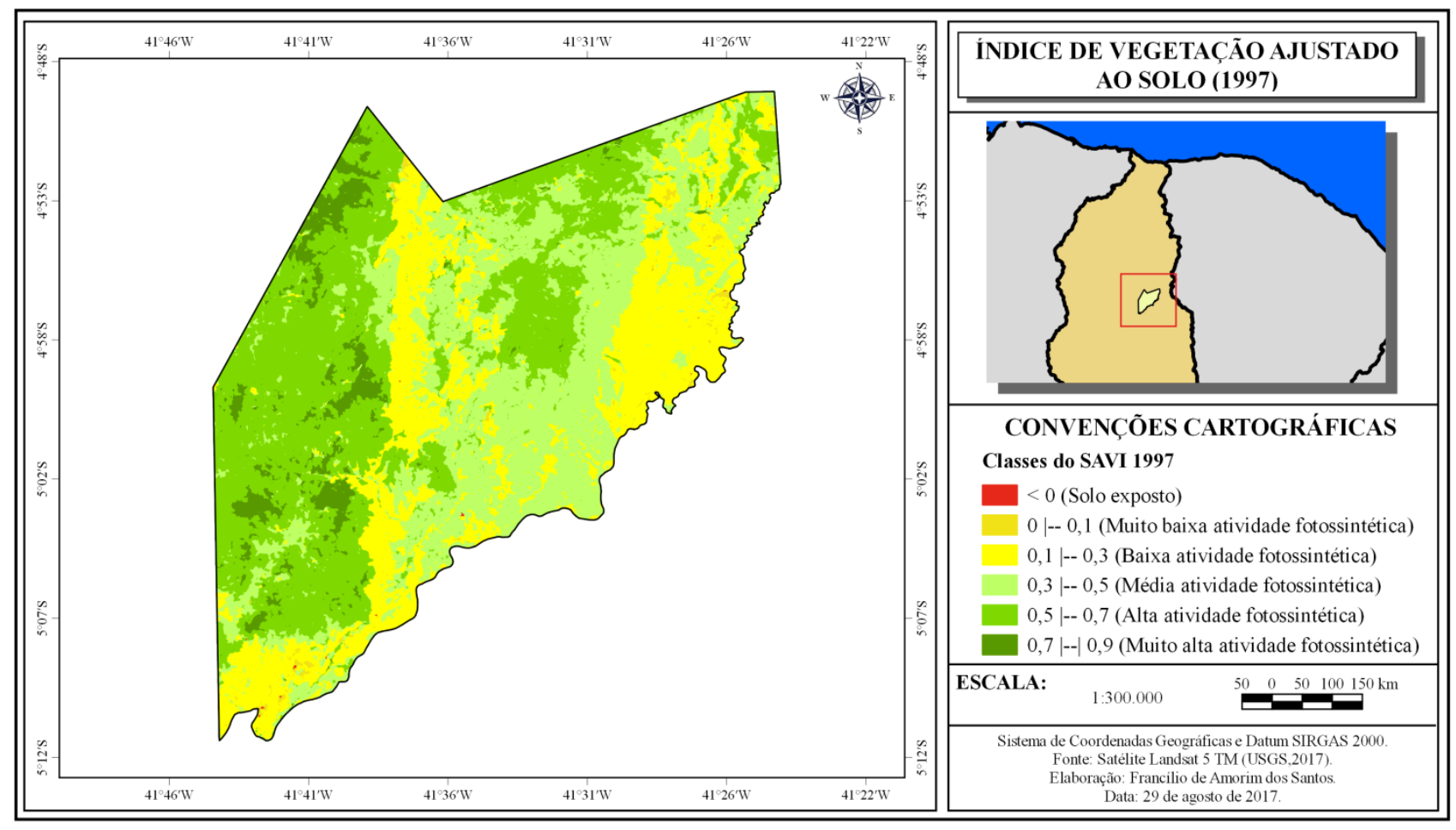

Figura 04. Índice de vegetação ajustado ao solo (SAVI) para o ano de 1997. Fonte: Sensor TM do satélite Landsat 5 (USGS, 2017). Elaborado pelo autor (2017).

Os dados inferidos pelo SAVI estão ligados ao fato de que na área estudada as folhas tendam a cair no segundo semestre do ano, como mecanismo adaptativo para evitar a perda de água por evapotranspiração. Tendo em vista que o índice é sensível à variação da quantidade de água, podese afirmar que possivelmente sofreu influência da baixa quantidade de água presente tanto no solo quanto na folhagem da vegetação, fato este justificado pela ocorrência de fenômeno El niño com transição de intensidade fraca para forte ocorrido de 1997 para 1998 (CPC, 2017).

Em relação ao ano de 2006, o SAVI apontou preponderância das classes alta a muito alta, que ocorreu em 58,4\% da área pesquisada, ocorrendo principalmente na parte oeste do município (Figura 05). Deve-se ressaltar que ambas as classes apresentaram um aumento da ordem de 16,8\% em relação ao ano de 1997, notadamente devido a ocorrência de fenômeno La niña de intensidade fraca (CPC, 2017), que resultou em quantidade de chuvas normais e maior absorção de água pela 
folhagem da vegetação. Com exceção da manutenção da classe solo exposto de 1997 para 2006, as demais classes apresentaram redução em suas áreas ocupadas, pois a classe muito baixa, baixa e média passaram a distribuir-se por $0,8 \%, 14,9 \%$ e $25,8 \%$, respectivamente.

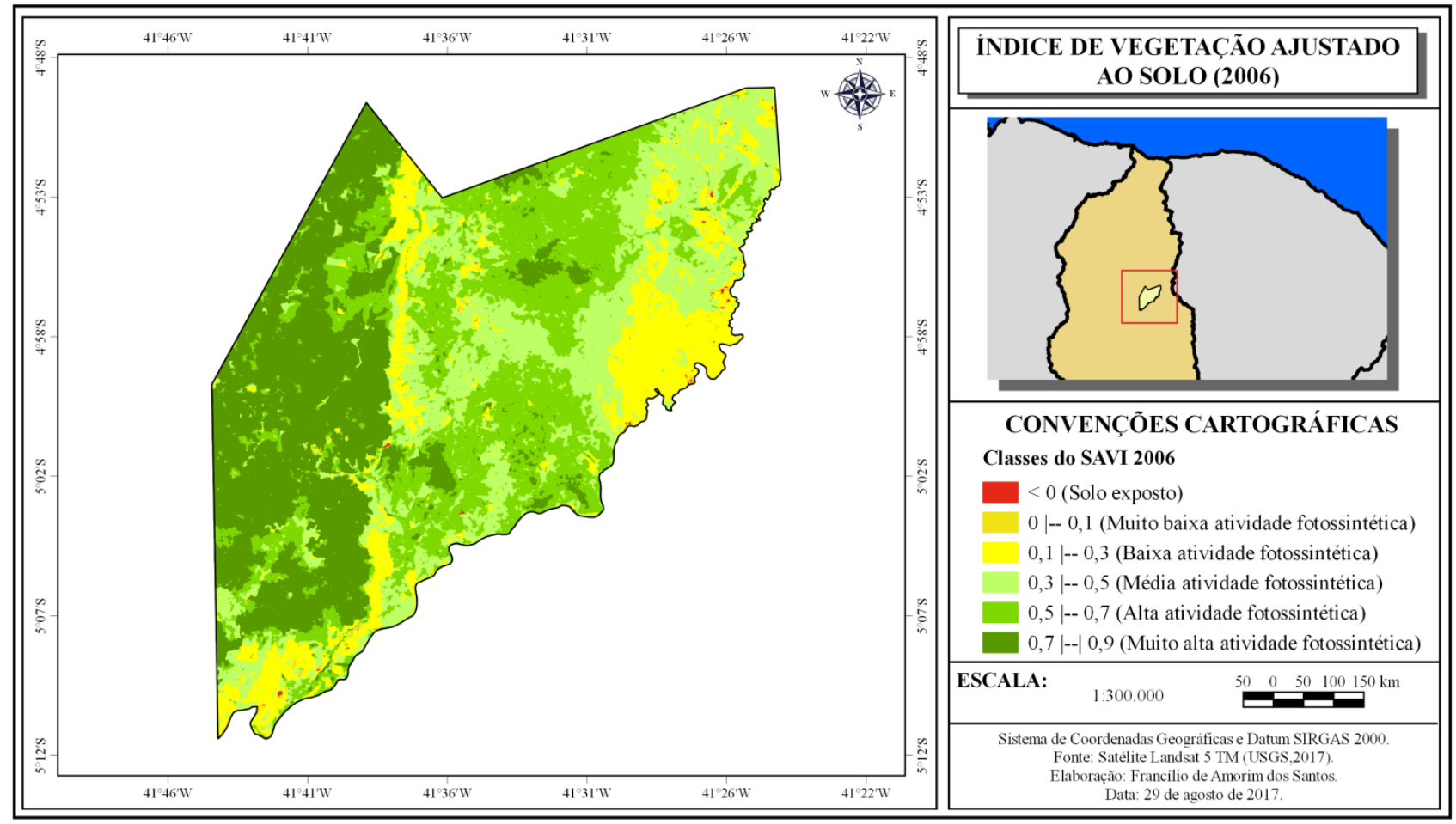

Figura 05. Índice de vegetação ajustado ao solo (SAVI) para o ano de 2006. Fonte: Sensor TM do satélite Landsat 5 (USGS, 2017). Elaborado pelo autor (2017).

A análise do SAVI para o ano de 2016 permitiu inferir que a classe baixa atividade fotossintética prevaleceu (Figura 06), visto que a mesma ocorreu por 85,15\% do município estudado, notadamente na parte centro-sul e nordeste. Diga-se, também, que as classes de solo exposto e muito baixa atividade fotossintética foi identificada por $0,02 \%$ e $0,58 \%$ do município, respectivamente. As classes de maior atividade fotossintética, média e alta, ocorreram em 14,22\% e $0,03 \%$ da área pesquisada, respectivamente.

Destaca-se que em 2015 e 2016 ocorreram fenômenos El niño, respectivamente, de intensidade fraca e forte (CPC, 2017). Nesse sentido, houve interferência direta na quantidade de água precipitada, particularmente abaixo da média e, por conseguinte, menor quantidade de água armazenada no solo e na folhagem das árvores, fato este detectado pelo índice espectral utilizado no presente estudo. 




Figura 06. Índice de vegetação ajustado ao solo (SAVI) para o ano de 2016. Fonte: Sensor OLI do satélite Landsat 8 (USGS, 2017). Elaborado pelo autor (2017).

\section{CONSIDERAÇÕES FINAIS}

Inicialmente, cabe destacar que o uso de índices espectrais para monitoramento da cobertura vegetal tem logrado grande êxito, principalmente no NEB. O SAVI, utilizado no presente estudo, possibilitou identificar a fisionomia da cobertura vegetal e seu estado de conservação/degradação no município de Juazeiro do Piauí, notadamente devido o município em questão está localizado em uma área suscetível ao processo de desertificação.

A metodologia utilizada possibilitou alcançar o objetivo proposto, tendo sido possível inferir que houve mudanças no padrão fisionômico da vegetação na área estudada, considerando-se os anos de 1997, 2006 e 2016. Tal fato gerou informações acerca da fisionomia do dossel vegetal, para os referidos anos, e deve contribuir para planejamento, gestão, monitoramento e aplicação de estratégias voltadas à conservação e da vegetação na área.

Nesse sentido, foi possível identificar que a cobertura vegetal do tipo caatinga apresenta fisionomia que varia do porte herbáceo a arbustivo e arbóreo. Ao passo que o SAVI indicou predomínio das classes de vegetação com atividade fotossintética alta e muito alta nos anos de 1997, quando ocupava 41,6\% do município, e 2006, onde se distribuída por 58,2\% da área 
estudada, sendo ambas as classes significativamente reduzidas no ano de 2016, quando figurou apenas a classe de atividade fotossintética alta, encontrado em 0,03\% do município.

Deve-se ressaltar que as mudanças nos padrões fisionômicos da vegetação possivelmente tenham sofrido influência da ocorrência dos fenômenos oceânicos El niño e La niña, visto que ambos são responsáveis pela ocorrência de anos secos e normais a chuvosos, respectivamente. Posto que por meio do SAVI tenha sido possível detectar a perda/ganho de água no que diz respeito à folhagem das plantas.

Diante disso, por meio das informações apresentadas constata-se a necessidade do uso de geotecnologias aliadas ao processamento digital de imagens e sensoriamento remoto como instrumento de monitoramento da dinâmica espaço-temporal da cobertura vegetal, principalmente em áreas suscetíveis à desertificação. Pois a redução ou ausência da cobertura vegetal pode levar ao desencadeamento de processos erosivos, com aumento do escoamento superficial e acentuação da vulnerabilidade dos solos à erosão, gerando desequilíbrios nos sistemas ambientais.

\section{REFERÊNCIAS}

ALBINO, R.S. Florística e fitossociologia da vegetação de cerrado rupestre de baixa altitude e perfil socioeconômico da atividade mineradora em Castelo do Piauí e Juazeiro do Piaú, Brasil. Dissertação (Mestrado em Desenvolvimento e Meio Ambiente) - Universidade Federal do Piauí - UFPI. Teresina - PI, 2005.

AGUIAR, R.B.; GOMES, J.R.C. (Org.). Projeto cadastro de fontes de abastecimento por água subterrânea, estado do Piauí: diagnóstico do município de Juazeiro do Piauí. - Fortaleza: CPRM Serviço Geológico do Brasil, 2004.

BORATTO, I.M.P.; GOMIDE, R.L. Aplicação dos índices de vegetação NDVI, SAVI e IAF na caracterização da cobertura vegetativa da região Norte de Minas Gerais. In: Simpósio Brasileiro de Sensoriamento Remoto, XVI, Foz do Iguaçu - PR, Anais... Foz do Iguaçu: SBSR, 2013, p.7345-7352.

BRASIL. Conferência das Nações Unidas sobre o Meio Ambiente e Desenvolvimento: de acordo com a Resolução no 44/228 da Assembléia Geral da ONU, de 22-12-89. Estabelece uma abordagem equilibrada e integrada das questões relativas a meio ambiente e desenvolvimento: Agenda 21. Brasília: Câmara dos Deputados, Coordenação de Publicações. 1995. 
BRASIL. Ministério do Meio Ambiente. Atlas das áreas susceptíveis à desertificação do Brasil. Secretaria de Recursos Hídricos. Universidade Federal da Paraíba; Marcos Oliveira Santana (Org.). Brasília: 2007.

BRASIL. Ministério do Meio Ambiente. Secretaria de Recursos Hídricos. Programa de Ação Nacional de Combate à Desertificação e Mitigação dos Efeitos da Seca PAN-Brasil. Brasília: MMA. 2004.

BRAZ, A.M.; ANDRADE ÁGUAS, T.; GARCIA, P.H.M. Análise de índices de vegetação NDVI e SAVI e Índice de Área Folear (IAF) para a comparação da cobertura vegetal na bacia hidrográfica do córrego ribeirãozinho, município de Selvíria-MS. Revista Percurso, v. 7, n. 2, p. 5-22, 2015.

CERQUEIRA, K.F.; SANTOS, F.A. Análise da cobertura vegetal, dos aspectos econômicos e a degradação ambiental do médio curso da Bacia Hidrográfica do rio Poti (Piauí), Nordeste do Brasil. ACTA Geográfica, v.11, n.26, mai./ago., p.160-172. 2017.

CPRM - Companhia de Pesquisa de Recursos Minerais. 2006. Mapas estaduais de geodiversidade: Piauí. Rio de Janeiro: CPRM. Documento cartográfico em arquivo vetorial. Disponível em <http://geobank.sa.cprm.gov.br>. Acesso em 15 de janeiro de 2014.

FERREIRA, A.G.; MELLO, N.G.S. Principais sistemas atmosféricos atuantes sobre a região Nordeste do Brasil e a influência dos Oceanos Pacífico e Atlântico no clima da região. Revista Brasileira de Climatologia, Curitiba - PR, vol.1, n.1, p.15-28. Dezembro de 2005.

FIGUEIRÊDO, A.C.; MONTENEGRO, A.A.A.; SANTOS, E.S.; GUERRA, S.M.S.; VILLAR, A.C.; GUSMÃO, L. Determinação de Índices de Vegetação para a análise da cobertura vegetal em bacia hidrográfica do Agreste pernambucano. In: Simpósio Brasileiro de Sensoriamento Remoto, XVI, Foz do Iguaçu - PR, Anais... Foz do Iguaçu: SBSR, 2013, p.7009-7015.

IBGE - Instituto Brasileiro de Geografia e Estatística. Banco de dados. Cidades. Disponível em <http://cidades.ibge.gov.br>. Acesso em 06 de setembro de 2017.

Malha municipal digital do Brasil: situação em 2015. Rio de Janeiro: IBGE. Disponível em <ftp://geoftp.ibge.gov.br/malhas_digitais/>. Acesso em 10 de abril de 2017.

Manual Técnico de Pedologia. $2^{\text {a }}$ edição. Rio de Janeiro, 2007.

INDE - Infraestrutura Nacional de Dados Especiais. Mapa de Solos da Folha SB.24 - Jaguaribe. Escala 1:250.000. Disponível em: 〈http://www.visualizador.inde.gov.br/>. 2014. Acesso em $27 \mathrm{de}$ novembro de 2015.

MENDONCA, F. Geografia física: ciência humana? - São Paulo: Contexto. 1989. 
MMA - Ministério do Meio Ambiente dos Recursos Hídricos e da Amazônia Legal. Download de dados geográficos. 2004. Disponível em: <http://mapas.mma.gov.br/i3geo/datadownload.htm>. Acesso em Acesso em 27 de agosto de 2015.

NIMER, E. Desertificação: realidade ou mito? Revista Brasileira de Geografia. Fundação Instituto Brasileiro de Geografia e Estatística, ano 50, n. 1, p.7-39, jan./mar. Rio de Janeiro: IBGE, 1988.

NOAA - National Oceanic and Atmospheric Administration. Climate Prediction Center. Historical El Nino / La Nina episodes (1950-2016). Disponível em <http://www.cpc.ncep.noaa.gov/products/analysis_monitoring/ensostuff/ensoyears.shtml>. Acesso em 09 de setembro de 2017.

SANTOS, F.A. Mapeamento das unidades geoambientais e estudo do risco de degradação/desertificação nos municípios de Castelo do Piauí e Juazeiro do Piauí. Dissertação (Mestrado em Geografia) - Programa de Pós-Graduação em Geografia (PPGGEO) / Universidade Federal do Piauí. 2015.

TRICART, J. Ecodinâmica. Rio de Janeiro, IBGE, Diretoria Técnica, SUPREN, 1977.

Recebido em: 15/08/2018

Aceite para publicação em: 05/11/2018 